\title{
Interleukin-1 Receptor Blockade Improves Survival and Hemodynamic Performance in Escherichia coli Septic Shock, but Fails to Alter Host Responses to Sublethal Endotoxemia
}

\author{
Eva Fischer," Michael A. Marano," Kimberly J. Van Zee," Craig S. Rock," Arthur S. Hawes, * William A. Thompson," \\ Laura DeForge," John S. Kenney," Daniel G. Remick," Duane C. Bloedow," \\ Robert C. Thompson," Stephen F. Lowry," and Lyle L. Moldawer* \\ ${ }^{*}$ Laboratory of Surgical Metabolism, Department of Surgery, Cornell University Medical College, New York 10021; ${ }^{\ddagger}$ Department of \\ Cellular Immunology, Syntex Research Laboratories, Palo Alto, California 94304; 'Department of Pathology, University of Michigan \\ Medical Center, Ann Arbor, Michigan 65432; and "Synergen, Inc., Boulder, Colorado 80301
}

\begin{abstract}
The present study was undertaken to evaluate the extent to which an endogenous interleukin-1 (IL-1) response contributes to the hemodynamic and metabolic consequences of sublethal endotoxemia or lethal Gram-negative septic shock. Young, healthy baboons received either a sublethal dose of lipopolysaccharide (LPS) or an $\mathrm{LD}_{100}$ of live Escherichia coli bacteria, and one half of the animals in each group were continuously infused with IL-1 receptor antagonist (IL-1ra). Plasma IL-1 $\beta$ was not detected in this model of endotoxemia. Administration of IL1ra had only minimal effects on the modest hemodynamic and metabolic responses to sublethal endotoxemia, and did not attenuate the plasma cytokine response. In contrast, high circulating levels of $\mathrm{IL}-1 \beta$ (range $300-800 \mathrm{pg} / \mathrm{ml}$ ) were seen during lethal $E$. coli septic shock. IL-1 ra treatment significantly attenuated the decrease in mean arterial blood pressure (MAP) (from $-72 \pm 8$ to $-43 \pm 6 \mathrm{~mm} \mathrm{Hg} ; P<0.05$ ) and cardiac output (from $-0.81 \pm 0.17$ to $-0.48 \pm 0.15 \mathrm{liter} / \mathrm{min} ; P<0.05$ ), and significantly improved survival from 43 to $100 \%$ at 24 h $(P<$ 0.05). The plasma IL-1 $\beta$ and IL-6 responses to lethal $E$. coli septic shock were also significantly diminished by IL-1ra treatment $(P<0.05)$, whereas tumor necrosis factor- $\alpha$ (TNF $\alpha)$ concentrations were unaffected. We conclude that an exaggerated systemic IL-1 $\beta$ response is characteristic of lethal $E$. coli septic shock, and contributes significantly to the hemodynamic and metabolic consequences of $E$. coli septic shock. IL-1ra can significantly attenuate the cytokine cascade and improve survival. (J. Clin. Invest. 1992. 89:1551-1557.) Key words: tumor necrosis factor $\bullet$ interleukin- $6 \cdot$ interleukin-8 $\cdot$ lipopolysaccharide
\end{abstract}

\section{Introduction}

IL-1 is a pleiotropic cytokine presumed to participate in the initiation and regulation of the acute-phase response to injury and infection (1). Endogenous IL-1 production contributes to the febrile and hepatic acute-phase protein responses, as well as to the anorexia and skeletal protein wasting seen during an acute inflammatory response $(2,3)$.

Address correspondence and reprint requests to Dr. Lyle L. Moldawer, F2016, The New York Hospital, 525 East 68th St., New York, NY 10021.

Received for publication 7 June 1991 and in revised form 30 December 1991.

J. Clin. Invest.

(c) The American Society for Clinical Investigation, Inc.

$0021-9738 / 92 / 05 / 1551 / 07 \$ 2.00$

Volume 89, May 1992, 1551-1557
Earlier investigations of the cytokine cascade initiated during Gram-negative septic shock have emphasized a proximal role for tumor necrosis factor- $\alpha$ (TNF $\alpha) .{ }^{1}$ Administration of TNF $\alpha$ to otherwise healthy animals induces cardiovascular collapse, multiorgan system failure, and death, similar to that seen in experimental lethal endotoxemia and in clinical sepsis (4). Passive immunization of primates with antibodies to TNF $\alpha$ improves survival in $E$. coli septic shock (5). However, an increasing body of evidence has also accumulated to suggest a role for IL-1 in the pathogenesis of Gram-negative septic shock.

We have recently reported that administration of recombinant human IL-1 $\alpha$ to healthy primates will result in hypotension and tachycardia similar to that seen in endotoxemia (6). Although quantities as low as $100 \mathrm{ng} / \mathrm{kg}$ body weight (BW) will produce significant tachycardia, $100 \mu \mathrm{g} / \mathrm{kg} \mathrm{BW}$ of IL- $1 \alpha$ decreases cardiac output and causes adrenal cortex hemorrhage. Okusawa and Dinarello also reported that administration of IL-1 $\beta$ to rabbits induced hypotension, decreased systemic vascular resistance, and central venous pressures, as well as increased heart rate and cardiac output (7). Furthermore, IL-1 $\beta$ potentiated the deleterious effects of TNF $\alpha(7,8)$. Ohlsson and colleagues have recently reported that an endogenous IL-1 response contributes to endotoxin-induced lethality, as treatment of rabbits with a newly described IL-1 receptor antagonist (IL-1 ra) improves survival (9). Similarly, Wakabayashi and Dinarello have observed that treatment of rabbits with IL-1 ra blunts hypotension in sublethal $E$. coli shock (10).

The present study was designed to examine the role of endogenously produced IL-1 in the hemodynamic and metabolic responses to a mild endotoxemia and to a lethal Gram-negative bacterial $(E$. coli $)$ infection in nonhuman primates. To inhibit the actions of endogenously produced IL-1, IL-1 ra was administered continuously during the course of mild endotoxemia and in lethal $E$. coli septic shock. A primate model of sublethal endotoxemia and lethal septic shock was chosen for several reasons. First, this $E$. coli septic shock model is well controlled, reproducible, and manifests many of the clinical responses seen in decompensated septic shock, such as a transient increase and subsequent decrease in cardiac output, hypotension, and tachycardia. Although the animals are provided crystalloid resuscitation, inotropic agents or ventilatory support are not employed. Second, similarities between human and Papio cytokines allow a full characterization of the cytokine response

1. Abbreviations used in this paper: BW, body weight; IL-1 ra, IL-1 receptor antagonist; MAP, mean arterial pressure; TNF- $\alpha$, tumor necrosis factor- $\alpha$. 
in sepsis. Antibodies against human IL- $\beta$, TNF $\alpha$, IL-8, and IL-1 ra all crossreact with the corresponding Papio mediators, but do not crossreact with either mouse or rabbit proteins. Third, the pharmacokinetics of human recombinant IL-1 ra in baboons would be expected to more closely approximate those in humans. Finally, this $E$. coli septic shock model has been used to explore the role of TNF $\alpha$ (5), allowing a direct comparison between the role of these two mediators.

In order to obtain a controlled and reproducible experimental septic shock model, a single bolus infusion of lethal quantities of $E$. coli was employed. However, this model differs from the pathogenesis of clinical septic shock which often originates from a nidus of infection. Furthermore, the interpretation of the results may be confounded to some degree as they are evaluated while the animal is in an anesthesized state, even though anesthetized control animals in previous studies have shown no significant hemodynamic changes (6).

The IL-1 ra employed in the present study is a $17-\mathrm{kD}$ recombinant human protein that shares $26 \%$ sequence homology with IL-1 $\beta$, binds to the IL-1 type I receptor with equal affinity, but has no agonist activity (11). When administered at a 1,000$M$ excess, IL-1 ra will block the hemodynamic and metabolic responses produced by IL- $1 \alpha$ administration (6).

\section{Methods}

Reagents. IL-1ra was produced at Synergen Inc. Before intravenous administration, the IL-1 ra was diluted with physiologic saline $(0.9 \%$ sodium chloride; $0.5 \mathrm{ml} / \mathrm{kg}$ [BW]). Control animals received equivalent amounts of human serum albumin (HSA). Salmonella typhosa lipopolysaccharide (LPS) (phenol extracted; lot 126F-4020) was obtained from Sigma Chemical Co. (St. Louis, MO). Lyophilized E. coli 086:B7 (obtained from Dr. G. T. Shires, Texas Tech. Univ. Lubbock, TX) was used to grow cultures on tryptic soy broth agar slants; viability counts of the inoculum were determined by standard dilution techniques. $E$. coli bacteria were diluted with physiologic saline to obtain a concentration of $10^{10}-10^{11} \mathrm{CFU} / \mathrm{ml}$.

Treatment of the animals. Young female baboons (Papio anubis) $(10-15 \mathrm{~kg})$ were housed and quarantined at the Research Animal Resource Center of Cornell University Medical College for 2-4 wk before study to confirm that they were in good health and free of transmissible diseases. Baboons were obtained through the National Primate Exchange by Buckshire Laboratories (Chelmsford, PA), and treated according to an experimental protocol approved by the Institutional Animal Care and Use Committee, Cornell University Medical College. The animal facility is registered with the U. S. Department of Agriculture and is fully accredited by the American Association for the Accreditation of Laboratory Animal Care. The Laboratory of Surgical Metabolism adheres to the Guide for the Care and Use of Laboratory Animals, as promulgated by the American Physiological Society.

Before the experiment, baboons were fasted overnight and immobilized with intramuscular ketamine hydrochloride $(10 \mathrm{mg} / \mathrm{kg} \mathrm{BW})$. During the study, anesthesia was maintained using sodium pentobarbital $(5 \mathrm{mg} / \mathrm{kg} \mathrm{BW}$ per h) intravenously to allow for spontaneous breathing. Control of the upper airway was obtained using an endotracheal tube $(6.5 \mathrm{~mm})$. Arterial and venous access were secured by sharply dissecting and bilaterally isolating the femoral vessels. Central pressures were monitored employing a balloon-tipped flow directed thermodilution pulmonary artery catheter (Swan-Ganz) placed via the femoral vein. One femoral artery was cannulated for blood pressure measurements and intermittent blood sampling. Continuous monitoring of the heart rate, systemic artery, pulmonary artery, and capillary wedge pressures was achieved with a Datascope (model 2000A; Datascope Corp., Paramus, NJ). Core temperature was recorded over the entire length of the study and maintained using a Mylar blanket. Hourly urine measurements were performed, using an urethral (Foley) catheter. Baseline hemodynamic parameters and blood collections were obtained over a 2 -h period immediately before initiation of the experiment.

Sublethal endotoxemia and lethal $E$. coli bacteremia were induced in 21 experimental animals by administration of $500 \mu \mathrm{g} / \mathrm{kg} \mathrm{BW} \mathrm{Salmo-}$ nella typhosa LPS $(n=7)$, or $10^{10}-10^{11} \mathrm{CFU} / \mathrm{kg}$ of live $E$. coli $(n=14)$, respectively. Before infusion of LPS or $E$. coli, the animals were assigned to receive either $10 \mathrm{mg} / \mathrm{kg}$ BW IL-1 ra followed by a continuous infusion of $25 \mu \mathrm{g} / \mathrm{kg} \mathrm{BW}$ per min of IL-1 ra $(n=11)$, or an equivalent amount of HSA $(n=10)$ for $8 \mathrm{~h}$. The protein and/or LPS were delivered into a central vein as a single bolus over $30 \mathrm{~s}$. The quantity of administered endotoxin was based on preliminary studies to produce a self-limited, mild endotoxemia associated with transient changes in heart rate and mean arterial blood pressures (MAP) (6). The live $E$. coli bacteria were infused over $30 \mathrm{~min}$ into the femoral vein. This quantity of bacteria represents an approximate $\mathrm{LD}_{100}$ dose of live $E$. coli (5). The bacterial dose was administered to pairs of baboons that were studied concurrently. After randomization, the assigned treatment was started simultaneously with the bacterial infusion. All investigators involved in performing the study were blinded as to the experimental treatment regimen.

Continuous infusions of physiologic saline ( $0.9 \%$ sodium chloride; $3 \mathrm{ml} / \mathrm{kg} \mathrm{BW}$ per h) were administered to all animals for $8 \mathrm{~h}$. In addition, $E$. coli septic animals were resuscitated during the first $8 \mathrm{~h}$ with 10 $\mathrm{ml} / \mathrm{kg} \mathrm{BW}$ of physiologic saline every $15 \mathrm{~min}$ if they met two or more of the following criteria: $(a)$ a $30 \%$ decrease in MAP; $(b)$ a $30 \%$ increase in heart rate; $(c)$ a pulmonary capillary wedge pressure (PCWP) of less than 2 torr; and $(d)$ urine output of less than $1 \mathrm{ml} / \mathrm{kg} \mathrm{BW}$. At $8 \mathrm{~h}$, fluid support was withdrawn from all animals and LPS baboons were killed by an intravenous injection of sodium pentobarbital $(100 \mathrm{mg} / \mathrm{kg} \mathrm{BW})$, whereas animals receiving $E$. coli were observed for survival until $24 \mathrm{~h}$. During the remaining $16 \mathrm{~h}, E$. coli-treated animals received $1.0 \mathrm{ml} / \mathrm{kg}$ per $\mathrm{h}$ BW of physiologic saline containing the IL-1 ra or placebo. Because of concerns regarding undue discomfort to nonhuman primates after induction of lethal $E$. coli septic shock, Institutional Animal Care and Use Committee guidelines required that the animals remained anesthetized for the duration of the study, and were euthanized at $24 \mathrm{~h}$.

Hemodynamic parameters and urine output were monitored continuously. At 30-min intervals for the first $3 \mathrm{~h}$, and at hourly intervals thereafter for $8 \mathrm{~h}$, arterial blood was collected. Arterial blood samples were also obtained at $24 \mathrm{~h}$ immediately before death. The plasma was stored at $-70^{\circ} \mathrm{C}$ until assays were performed.

Analytical methods. Plasma IL-1 $\beta$ and TNF $\alpha$ were measured by standard ELISA techniques, as reported elsewhere $(12,13)$. The sensitivity of the assays are 30 and $34 \mathrm{pg} / \mathrm{ml}$, respectively. Plasma IL-8, a recently described cytokine with neutrophil chemotactic properties, was also measured by ELISA with a sensitivity of $80 \mathrm{pg} / \mathrm{ml}$ (14). An ELISA was used to determine IL-1 ra concentrations. A polyclonal rabbit antibody raised against recombinant human IL-1 ra and purified by affinity chromatography was employed as the capture antibody. The affinity-purified antibody was also biotinylated, and a horse radish peroxidase conjugated to avidin was used to visualize the captured protein. The lower limit of detection for this assay is $600 \mathrm{pg} / \mathrm{ml}$. IL-6 activity was determined using the B.9 hybridoma cell proliferation assay (15). One unit of activity is defined as the quantity of IL-6 required to produce half-maximal proliferation (lower limit of detection $10 \mathrm{~B} .9 \mathrm{U} / \mathrm{ml}$ ).

Plasma glucose was measured using an automated glucose oxidase analyzer (Glucose Analyzer 2; Beckman Instruments Inc., Sunnyvale, CA). Lactate was measured enzymatically, according to the manufacturer's instructions (model 826-UV; Sigma Chemical Co.).

Prothrombin times, partial thromboplastin times, platelet counts, fibrinogen, fibrin split products, and complete blood chemistries were all measured at the clinical laboratories of the Animal Medical Center, New York. Arterial and mixed venous oxygen and carbon dioxide concentrations were assessed with a clinical blood gas analyzer (pH/Blood Gas Analyzer 1306; Instrumentation Laboratory, Inc., Lexington, 
MA). Total white blood cell counts were performed using a Coulter counter (Coulter Electronics, Hialeah, FL).

Statistical analyses. Data were analyzed with a microcomputerbased commercial statistical package (StatPac ${ }^{\circledR}$; Northwest Analytical, Portland, OR). Changes in hemodynamic, hematologic, and hormonal/metabolic responses due to time, and the individual treatment regimens were analyzed by one-and two-way analysis of variance. Comparisons between groups were performed using Newman-Keuls' multiple range test. Statistical significance was designated at the $95 \%$ confidence level.

\section{Results}

Sublethal endotoxemia. Baboons receiving $500 \mu \mathrm{g} / \mathrm{kg} \mathrm{BW}$ of Salmonella typhosa LPS showed only a $17 \%$ decrease in MAP, and a $44 \%$ increase in heart rate (both $P<0.05$ ). Pulmonary capillary wedge pressures (PCWP) also declined (data not shown), whereas cardiac output was unaffected. IL-1 ra treatment had no significant effect on changes in tachycardia, cardiac output, and MAP produced by this mild degree of endotoxemia (Fig. 1).

LPS induced a systemic TNF $\alpha$ and IL-6 response that were unaffected by IL-1 ra treatment (Fig. 2). IL-8 levels were also unchanged by IL-1 ra treatment. IL- $1 \beta$ was only randomly detected in the plasma in either group at a sensitivity of $30 \mathrm{pg} / \mathrm{ml}$.

After endotoxin administration, total leukocyte numbers declined, reaching a nadir at $2 \mathrm{~h}$ (Fig. 3), and rose again so that total leukocyte numbers were normal at $8 \mathrm{~h}$. IL-1 ra administration did not prevent the leukopenia or subsequent leukocytosis that developed after endotoxemia. Platelet counts, fibrinogen concentrations, and fibrin split products were unaffected by this degree of endotoxemia (data not shown) in all animals.

Arterial blood glucose and lactate levels (data not shown) increased in all endotoxin-treated baboons $(P<0.05)$, and the changes were unaffected by IL-1 ra teatment.
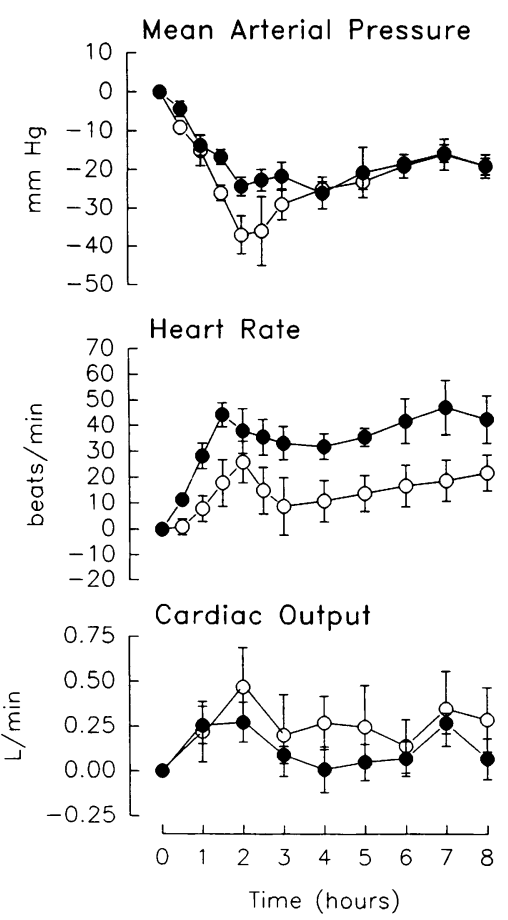

Figure 1. Changes in hemodynamic performance in baboons during sublethal endotoxemia and IL-1 ra or placebo administration. Baboons were anesthetized and instrumented, as described in Methods. Animals received $500 \mu \mathrm{g} / \mathrm{kg} \mathrm{BW}$ of $\mathrm{Sal}$ monella typhosa LPS and were infused with either bolus of $10 \mathrm{mg} / \mathrm{kg}$ BW i.v. followed by 25 $\mu \mathrm{g} / \mathrm{kg} \mathrm{BW}$ per min of IL-1 ra (open circles), or placebo (closed circles). Sublethal endotoxemia produced a mild hypotension and tachycardia that were not significantly affected by IL-1 ra treatment. Cardiac output was similarly unaffected by either endotoxemia or IL-1 ra treatment.

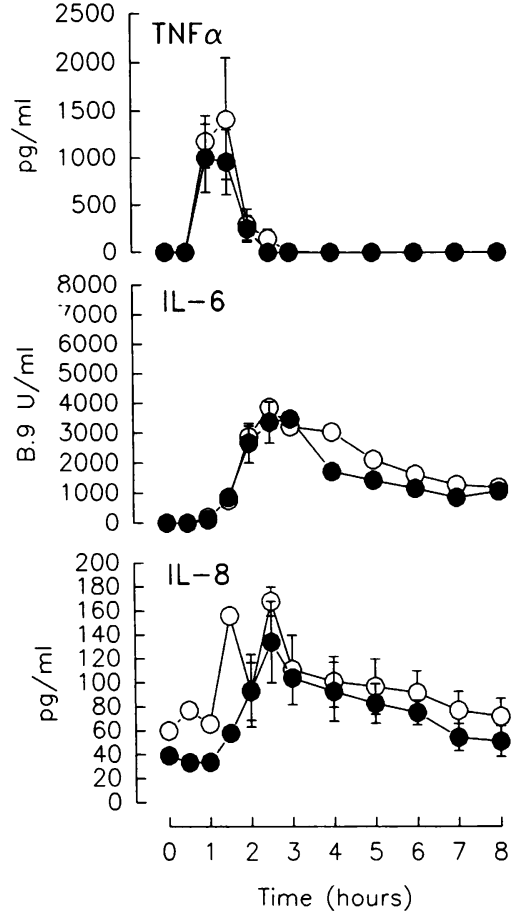

Figure 2. Cytokine production during endotoxemia and effect of IL-1 ra treatment. TNF $\alpha$, IL-6, and IL-8 were measured, as described in Methods. TNF $\alpha$, IL-6, and IL-8 concentrations were unaffected by IL-1 ra treatment. IL- $1 \beta$ could not be detected at a sensitivity of $30 \mathrm{pg} / \mathrm{ml}$ in this model (closed circles represent placebotreated animals, and open circles IL-1 ratreated animals).

Lethal E. coli septic shock. MAP and cardiac output declined precipitously in control baboons receiving $E$. coli, after a transient increase in cardiac output in the first $2 \mathrm{~h}$. Baboons became significantly tachycardic within $45 \mathrm{~min}$ of administer-
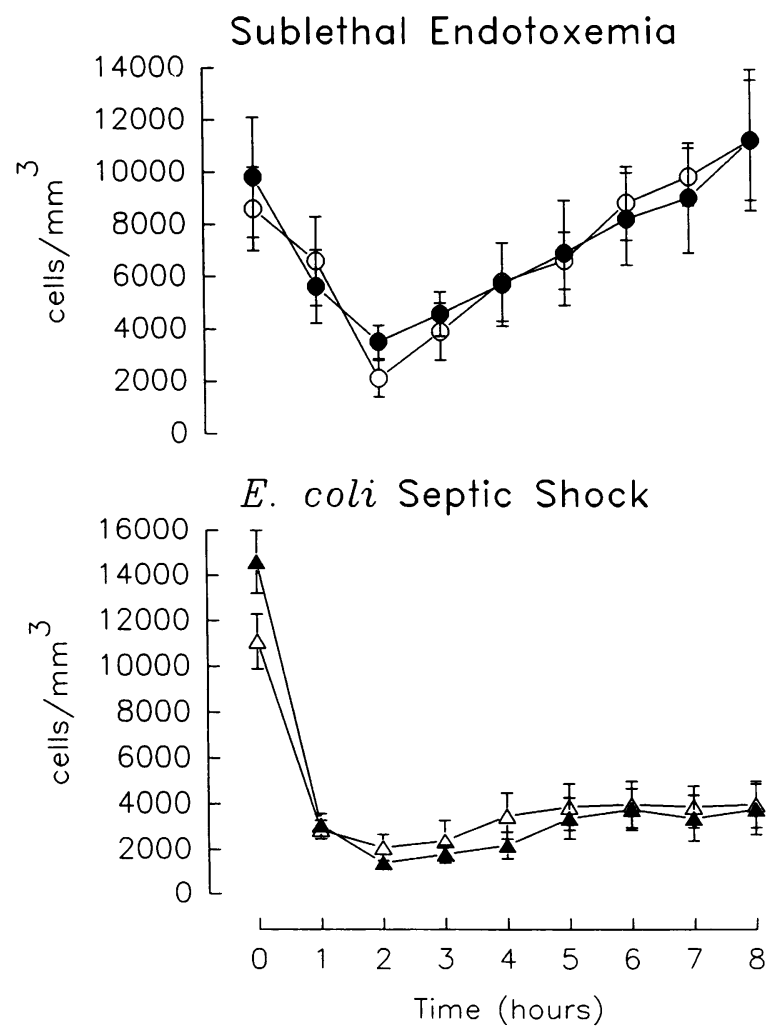

Figure 3. Leukocyte changes in baboons treated with IL-1 ra or placebo during sublethal endotoxemia or lethal $E$. coli septic shock. Baboons were treated, as described in Methods. IL-1 ra (open circles and open triangles, respectively) treatment had no effect on the leukocyte changes after sublethal endotoxemia and in lethal $E$. coli septic shock. 
ing $E$. coli. Fluid resuscitation was instituted once predetermined hemodynamic criteria were met. During the first $8 \mathrm{~h}$, $1,539 \pm 556 \mathrm{ml}$ of $0.9 \%$ sodium chloride were administered in an effort to maintain hemodynamic performance. However, four of seven control baboons expired ( $57 \%$ mortality) within the first $24 \mathrm{~h}$ despite efforts to resuscitate the animals. One of the three remaining animals had significant organ dysfunction at death at $24 \mathrm{~h}$; the animal was anuric and had a plasma creatinine of $5.2 \mathrm{mg} / \mathrm{dl}$ (baseline range $<1.0 \mathrm{mg} / \mathrm{dl}$ ).

IL-1ra treatment. After the bolus infusion of $10 \mathrm{mg} / \mathrm{kg} \mathrm{BW}$ IL-1 ra and during the infusion of $25 \mu \mathrm{g} / \mathrm{kg} \mathrm{BW}$ per min, plasma IL-1 ra levels declined from a measured maximum of $50 \pm 4$ $\mu \mathrm{g} / \mathrm{ml}$ at $1 / 2 \mathrm{~h}$ to a plateau of $7.3 \pm 0.2 \mu \mathrm{g} / \mathrm{ml}$ beginning at about 2 $\mathrm{h}$. This plateau continued for 6 to $8 \mathrm{~h}$. Plasma IL-1 ra clearances during this period ranged from 2.0 to $6.0 \mathrm{ml} / \mathrm{min}$ per $\mathrm{kg} \mathrm{BW}$ (mean $3.3 \pm 0.3 \mathrm{ml} / \mathrm{min}$ per $\mathrm{kg} \mathrm{BW}$ ). In two of the baboons, however, plasma IL-1 ra levels increased to 65 and to $120 \mu \mathrm{g} /$ $\mathrm{ml}$, respectively. Although these plasma IL-1 ra levels are not steady-state levels, they do suggest decreased plasma IL-1 ra clearances $(0.40$ and $0.23 \mathrm{ml} / \mathrm{min}$ per $\mathrm{kg} \mathrm{BW}$, respectively). The pronounced increases in plasma IL-1 ra during the 8 to 24-h time period in two of the IL-1ra-treated animals were accompanied by increases in serum creatinine and BUN, suggesting a relationship between renal function and IL-1 ra clearance. Across all baboons, plasma IL-1 ra levels correlated well with simultaneously measured serum creatinine concentrations $\left(P<0.0001, R^{2}=0.89\right)$.

$E$. coli septic animals receiving IL-1 ra also became hypotensive, but the transient increase and subsequent decline in cardiac output and MAP were not as precipitous as observed in baboons receiving placebo (Fig. 4). Fluid resuscitation was provided when the animals met predetermined criteria. As a result, crystalloid support during resuscitation tended to be lower in IL-1 ra-treated baboons than in placebo-treated controls $(771 \pm 259$ vs $1539 \pm 556 \mathrm{ml})$. However, as shown in Fig. 5 , these animals responded to fluid support by maintaining their MAP, whereas in placebo-treated animals, fluid support was unable to restore or maintain hemodynamic performance. Survival over the first $24 \mathrm{~h}$ was $100 \%$ ( 7 of 7$)(P=0.03$ by Fisher's exact
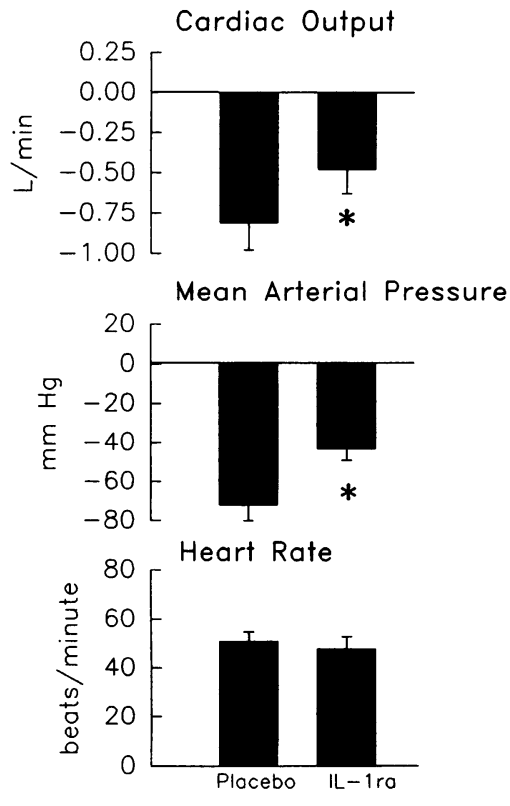

Figure 4. Changes in hemodynamic performance in $E$. coli septic shock baboons: IL-1 ra treatment vs placebo. Maximal changes in MAP, cardiac output, and heart rate over the first $8 \mathrm{~h}$ in $E$. coli shock baboons treated with either IL-1 ra or placebo. The differences in MAP and cardiac output in the two groups were statistically significant $\left({ }^{*} P\right.$ $<0.05$ by paired $t$ test). test vs placebo-treated baboons); however one of the IL-1ratreated animals was anuric and had an elevated serum creatinine $(3.5 \mathrm{mg} / \mathrm{ml} \mathrm{vs}<1.0 \mathrm{mg} / \mathrm{ml}$ at baseline $)$.

Animal welfare concerns necessitated terminating the study after $24 \mathrm{~h}$. However, six of the seven animals given IL-1 ra would likely have survived the acute response to $E$. coli, as 24-h indices of renal, hepatic, and pulmonary function were all within normal limits. As previously stated, one of the IL-1 ratreated $E$. coli septic animals was anuric and was likely to have ultimately expired. This contrasts with the control group where four of seven expired within the first $24 \mathrm{~h}$, and one of the survivors was anuric. In this case, only two of the seven placebo-treated animals were free of significant organ dysfunction and likely to have been long-term survivors, whereas in the IL-1 ra group, the number of long-term survivors would likely have been six of seven ( $P=0.05$ by Fisher's exact test).

During $E$. coli septic shock, plasma TNF $\alpha$ concentrations peaked at 90 min and disappeared by $3 \mathrm{~h}$ (Fig. 6); IL-1 ra infusions had no effect on these levels. In contrast, IL- $1 \beta$ appeared in the circulation within $2 \mathrm{~h}$ and remained elevated for the entire $24 \mathrm{~h}$, and these concentrations were significantly reduced in the IL-1ra-treated baboons, compared with their sham-treated counterparts. IL- 6 and IL-8 were also detectable
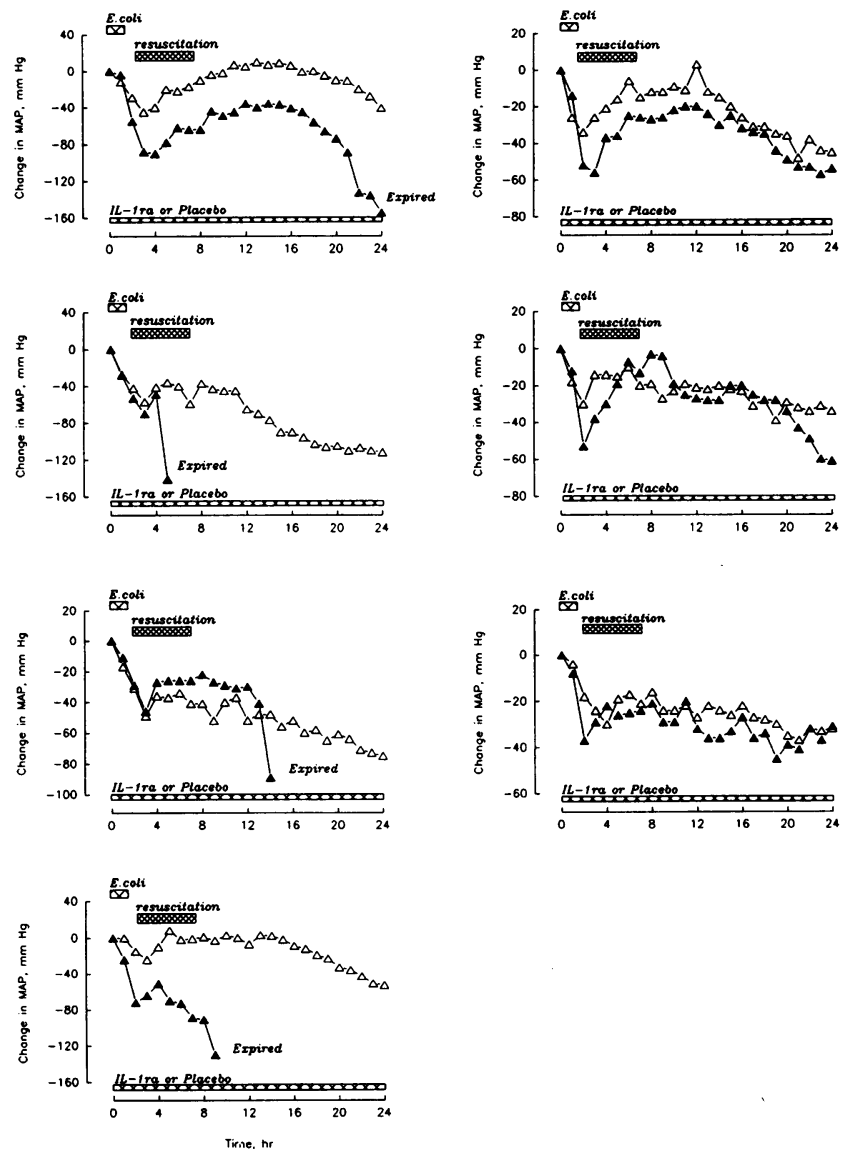

Figure 5. Changes in MAP in E. coli septic baboons: IL-1 ra treatment vs placebo. $E$. coli septic shock was induced in baboons in a blinded and random fashion, one animal from each pair received IL-1 ra at $10 \mathrm{mg} / \mathrm{kg} \mathrm{BW}$ followed by $25 \mu \mathrm{g} / \mathrm{kg}$ BW per min (open triangles) while the other received placebo (closed triangles). MAP was evaluated continuously over the subsequent $24 \mathrm{~h}$. Animals were resuscitated over the initial 8-h period with crystalloid according to preset criteria, as described in Methods. 

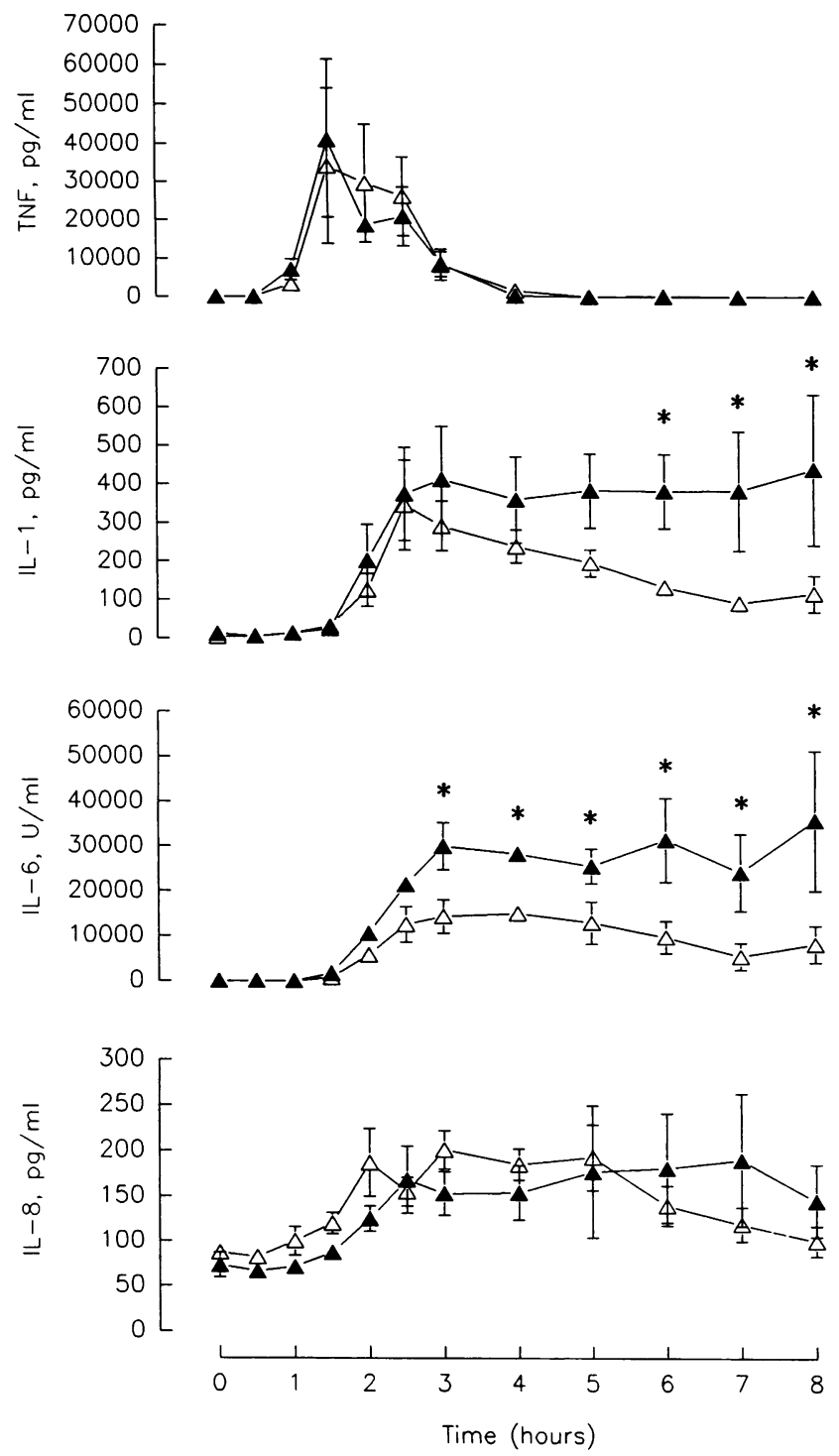

Figure 6. Cytokine levels during E. coli septic shock and effect of IL1 ra treatment. IL-1 ra (open triangles) significantly decreased the plasma IL-6 response and attenuated the sustained IL- $1 \beta$ response in $E$. coli shock when compared with placebo-treated animals (closed triangles $)\left({ }^{*} P<0.05\right.$ by ANOVA and Newman-Keuls MRT). TNF $\alpha$ and IL-8 concentrations were unaffected by IL-1ra treatment.

within $3 \mathrm{~h}$ and remained elevated throughout the 24-h study period. The IL-6 levels were reduced, but the IL-8 levels were unaffected by IL-1 ra treatment.

Blood glucose decreased transiently in $E$. coli septic baboons. Lactate levels increased continuously over the study period, reaching $44 \pm 18 \mathrm{mg} / \mathrm{dl}$, approximately two times that seen in sublethal endotoxemia. IL-1 ra treatment had no significant effect on the lacticacidemia (Table I). However, IL-1 ra treatment significantly minimized the nadir hypoglycemia seen during lethal $E$. coli septic shock (nadir $48 \pm 4$ vs $62 \pm 6$ $\mathrm{mg} / \mathrm{dl} ; P<0.05$ ). The other parameters were unaffected by IL-1 ra (Table I).

Total white blood cell numbers declined in $E$. coli septic animals and remained suppressed over the course of the study (Fig. 3). IL-1 ra treatment had no effect on the leukopenia. In both control and treatment groups, the leukopenia was asso- ciated with decreased numbers of lymphocytes, polymorphonuclear cells, and monocytes, as well as increased number of immature polymorphonuclear leukocytes (data not shown). Control baboons receiving $E$. coli rapidly developed thrombocytopenia, fibrinogen levels declined, and by $8 \mathrm{~h}$ after $E$. coli administration, all animals had fibrinogen split products detectable in the blood (Table I). IL-1 ra treatment did not prevent thrombocytopenia, but delayed the appearance of fibrin split products in the blood.

\section{Discussion}

This study used an IL-1 receptor antagonist to elucidate the role of endogenous IL-1 on the metabolic and hemodynamic responses to a sublethal endotoxemia and to lethal Gram-negative septic shock. IL-1 ra is a $22-24-\mathrm{kD}$ cytokine produced in vitro by blood monocytes and tissue macrophages. With an affinity similar to that of IL- $\beta$, IL- 1 ra binds preferentially to the IL-1 type I receptor that is found primarily on T lymphocytes, endothelial cells, tissue macrophages, and hepatocytes. However, IL-1 ra has weaker affinity than IL- $1 \alpha$ for the type II receptor found principally on blood neutrophils and B cells $(11,16)$. IL-1 ra has no known agonist activities, and administration of $10 \mathrm{mg} / \mathrm{kg} \mathrm{BW}$ of IL-1 ra to healthy primates is without any detectable biologic response (6). Because of the relatively rapid clearance of the protein in the circulation, IL-1 ra was administered in the present study as a primed-continuous infusion that achieved circulating plasma concentrations at least 1,00010,000 -fold in molar excess to circulating IL- $1 \beta$. In previous primate studies, we observed that this molar excess of IL-1 ra was sufficient to prevent the hemodynamic and physiologic responses to exogenously administered IL-1 $\alpha$ (6). The early rapid decline in plasma IL-1 ra levels following the intravenous loading dose is consistent with rapid distribution and efficient plasma clearance of IL-1 ra. The plateau plasma IL-1 ra concentration during the initial 2-8-h period indicate constant plasma IL-1 ra clearance over this time period. The estimated IL-1 ra plasma clearance $(2.0-6.0 \mathrm{ml} / \mathrm{min}$ per $\mathrm{kg} \mathrm{BW})$ reflect relatively efficient metabolic processing for IL-1 ra in the baboon.

The findings presented here demonstrate that treatment of primate $E$. coli septic shock with an IL-1 receptor antagonist improves survival. The most profound improvements observed after $E$. coli administration and IL-1 ra treatment were the preservation of cardiac output and MAP. During endotoxin-induced shock in rabbits, Ohlsson and colleagues were also able to demonstrate reduced lethality and significantly decreased tissue damage when animals were treated with IL-1 ra (9). In the present study, the improvement in outcome with IL-1 receptor blockade occurred despite the absence of any significant attenuation in plasma TNF $\alpha$ levels. The present findings demonstrate that endogenous TNF $\alpha$ production can not by itself explain the pathophysiologic consequences of lethal $E$. coli septic shock. Rather, they suggest that IL-1, or mediators induced by IL-1, contribute significantly to this toxicity. However, in earlier primate studies, exogenous IL-1 was unable to produce irreversible shock and widespread tissue damage (6), arguing that endogenous IL-1 by itself cannot explain the lethal effects of Gram-negative or endotoxemic shock. Rather, the data imply that IL-1 contributes to and potentiates TNF $\alpha$-induced cardiovascular collapse.

IL-1 ra administration significantly decreased the plasma 


\begin{tabular}{|c|c|c|c|c|c|c|c|c|}
\hline \multirow[b]{2}{*}{ Time $(h)$} & \multicolumn{4}{|c|}{ E. coli septic } & \multicolumn{4}{|c|}{ E. coli + IL-1ra } \\
\hline & $\begin{array}{c}0 \\
(n=7)\end{array}$ & $\begin{array}{c}8 \\
(n=6)^{*}\end{array}$ & $\begin{array}{c}16 \\
(n=4)^{\ddagger}\end{array}$ & $\begin{array}{c}24 \\
(n=3)^{8}\end{array}$ & $\begin{array}{c}0 \\
(n=7)\end{array}$ & $\begin{array}{c}8 \\
(n=7)\end{array}$ & $\begin{array}{c}16 \\
(n=7)\end{array}$ & $\begin{array}{c}24 \\
(n=7)\end{array}$ \\
\hline \multicolumn{9}{|l|}{ Metabolic indices } \\
\hline Glucose, $m g / d l$ & $70 \pm 3$ & $57 \pm 7^{11}$ & $83 \pm 6$ & $94 \pm 11$ & $75 \pm 5$ & $74 \pm 6$ & $88 \pm 5$ & $84 \pm 4$ \\
\hline Lactate, $m g / d l$ & $10 \pm 1$ & $35 \pm 12$ & $27 \pm 3$ & $44 \pm 18$ & $9 \pm 1$ & $22 \pm 3$ & $37 \pm 6$ & $40 \pm 9$ \\
\hline \multicolumn{9}{|l|}{ Hematologic indices } \\
\hline Thrombocyte, cells $/ \mathrm{mm}^{3}\left(\times 10^{3}\right)$ & $372 \pm 39$ & $151 \pm 51$ & $71 \pm 11$ & $53 \pm 5$ & $379 \pm 67$ & $122 \pm 30$ & $83 \pm 20$ & $43 \pm 10$ \\
\hline Fibrinogen, $m g / d l$ & $10 \pm 2$ & $17 \pm 3$ & $15 \pm 5$ & $13 \pm 5$ & $10 \pm 3$ & $17 \pm 4$ & $17 \pm 4$ & $17 \pm 5$ \\
\hline Fibrin split products, No. positive per total No. & $0 / 7$ & $4 / 6$ & $3 / 4$ & $2 / 3$ & $0 / 7$ & $1 / 7$ & $5 / 7$ & $6 / 7$ \\
\hline Prothrombin time, $s$ & $15 \pm 1$ & $24 \pm 2$ & $22 \pm 3$ & $18 \pm 3$ & $18 \pm 1$ & $18 \pm 1$ & $19 \pm 3$ & $19 \pm 3$ \\
\hline Partial thromboplastin time, $s$ & $52 \pm 7$ & $42 \pm 5$ & $53 \pm 7$ & $55 \pm 8$ & $46 \pm 8$ & $49 \pm 5$ & $55 \pm 7$ & $57 \pm 9$ \\
\hline Hematocrit & $36 \pm 1$ & $28 \pm 3$ & $26 \pm 3$ & $23 \pm 4$ & $37 \pm 1$ & $31 \pm 1$ & $27 \pm 2$ & $23 \pm 2$ \\
\hline
\end{tabular}

* The mean is calculated among six animals who survived at this time point. ${ }^{\ddagger}$ Similarly, there are four baboons alive and the mean is calculated among them. ${ }^{\S}$ At this time point there are only three animals that survived and the mean represents them. $" P<0.05$.

IL-6 response during lethal $E$. coli bacteremia. Similarly, pretreatment with anti-TNF $\alpha$ antibody leads to a diminished IL-6 response in $E$. coli septic shock (15). In a recent report, Starnes and colleagues reported that treatment of rats with a monoclonal antibody against murine IL-6 improved survival in $E$. coli shock (17). The authors have argued that IL-6 may be the terminal mediator of the pathologic responses to $E$. coli septic shock, and TNF $\alpha$ or IL-1 toxicity may be attributed to their capacity to induce a circulating IL- 6 response. The present findings are not in disagreement with this conclusion, but are difficult to reconcile with the observations that IL-1 is equivalent to TNF $\alpha$ as an in vivo inducer of IL-6 (18), yet IL-1 is much less toxic than TNF $\alpha$ when exogenously administered, and that IL-6 has no known toxicity when infused into healthy animals. We have administered quantities exceeding $10 \mathrm{mg} / \mathrm{kg} \mathrm{BW}$ to mice and have observed no evidence of toxicity (unpublished data). Similarly, Preiser and colleagues have also administered IL-6 to dogs and have reported no untoward hemodynamic effects (19).

Rather surprisingly, IL-1 ra administration attenuated the plasma IL- $1 \beta$ response to $E$. coli bacteremia in this model. These findings are in partial disagreement with those from similar studies in $E$. coli shock in rabbits. Although Wakabayashi and Dinarello were able to show that IL-1 receptor blockade could attenuate hypotension in a sublethal $E$. coli shock model in rabbits (10), the authors were unable to demonstrate a significant IL- $1 \beta$ decline in IL-1 ra-treated animals. The discrepancy may be explained by differences in the severity of the two $E$. coli septic shock models. In both studies, the early hemodynamic changes are similar and most likely due to the direct effect of the injurious stimulus, as well as mediated by TNF $\alpha$. Mortality in the Wakabayashi study was $40 \%$ after administration of killed $E$. coli bacteria; with the present model, early mortality was $57 \%$ after infusion of live E. coli, and long-term mortality approached $75 \%$. Furthermore, the magnitude of the IL- $1 \beta$ response was markedly higher in the present study. In untreated $E$. coli septic baboons, the IL- $1 \beta$ response lasted 24 $h$, whereas in rabbit studies, the IL- $1 \beta$ response had returned to baseline within $5 \mathrm{~h}(10)$. In the present investigation, IL-1 ra treatment did not block the initial production of IL- $1 \beta$, but prevented a sustained response. This initial spike in IL- $1 \beta$ re- fractory to IL-1 ra treatment is likely the direct result of $E$. coli bacteremia, endotoxemia, and the subsequent endogenous TNF $\alpha$ response, all of which can induce IL-1 production (20). The resulting decline in IL- $1 \beta$ levels may be explained by IL1 ra inhibition of IL- $1 \beta$ synthesis, as in vitro studies have shown that IL- $1 \beta$ can induce IL- $1 \beta$ gene transcription in an autocrine manner (21).

The differences in severity between this and the rabbit model of Wakabayashi can also explain the failure of IL-1 ra to attenuate the leukopenia observed in the present study. In rabbits receiving sublethal $E$. coli infections, total white cell numbers declined by only $60 \%$, and IL-1 ra treatment attenuated this response by $\sim 30 \%(10)$. In the present study, E. coli septic shock produced greater than $90 \%$ reduction in circulating white cell numbers, and the numbers were unaffected by IL-1 ra treatment.

In comparison to $E$. coli shock, IL-1 ra treatment had only minimal effects on the hemodynamic, substrate, and white cell responses to a sublethal endotoxemia. The absence of a systemic response to IL-1 ra during sublethal endotoxemia was surprising and unanticipated. Whereas IL-1 ra treatment attenuated the hemodynamic changes and the plasma IL-6 response in lethal $E$. coli septic shock, it had no apparent effect during endotoxemia, suggesting that these responses to sublethal endotoxin administration are relatively IL- 1 independent. The failure of IL-1 ra to block the hypotension and IL-6 responses during endotoxemia cannot be easily explained by an inability of the receptor antagonist to block IL-1 mediated responses. It is unlikely that preservation of these responses can be explained by IL-1's actions on the type II receptor, as previous baboon studies have shown that IL-1 receptor antagonist will block the hypotension and IL- 6 responses to exogenous IL- $1 \alpha$ administration (6).

Controversy exists whether a systemic IL-1 response occurs at all during sublethal endotoxemia. Previous studies from this laboratory have failed to show a circulating plasma IL- $1 \beta$ response to endotoxemia in human volunteers (22). Michie et al. were also unable to detect circulating IL- $1 \beta$ in volunteers receiving endotoxin (12). However, Cannon et al. have recently reported increased IL- $1 \beta$ at a single time point following endotoxin administration (23). The present results would suggest 
that circulating IL-1 is not likely to occur, or responsible for, most of the hemodynamic changes observed in sublethal endotoxemia.

In contrast, the severity of the infectious stimulus in the septic shock model correlates with the magnitude of the exaggerated IL- 1 response, and hence its detection in the circulation. Therefore, we conclude that IL- 1 is not the principal mediator of the hemodynamic and pathophysiologic responses to sublethal endotoxemia. However, excessive IL-1 production contributes to the pathophysiologic responses to lethal $E$. coli infection. Furthermore, IL-1 receptor antagonist may be beneficial in the treatment of hospitalized patients at risk of developing septic shock.

\section{Acknowledgments}

The authors wish to gratefully acknowledge the assistance of Arlene A. Hudson in completing these primate studies. Additional analytical assistance was provided by Jacqueline Sjöberg and Christopher Keogh. Assistance with animal care and hematological analyses was kindly provided by Anita Piccolie, Girma Asfaw, and Eileen Weiner.

Supported by grants GM-40586, GM-34695 and CA-52108, awarded by the National Institutes of Health, United States Public Health Service.

\section{References}

1. Fong, Y., L. L. Moldawer, G. T. Shires, and S. F. Lowry. 1990. The biologic characteristics of cytokines and their implication in surgical injury. Surg. Gynecol. Obstet., 170:363-378.

2. Long, N. C., I. Otterness, S. L. Kunkel, A. J. Vander, and M. J. Kluger. 1990. Roles of interleukin- $1 \beta$ and tumor necrosis factor in lipopolysaccharide fever in rats. Am. J. Physiol. 259:R724-R728.

3. Gershenwald, J. E., Y. Fong, T. J. Fahey III, S. E. Calvano, R. Chizzonite, P. L. Kilian, S. F. Lowry, and L. L. Moldawer. 1990. Interleukin-1 receptor blockade attenuates the host inflammatory response. Proc. Natl. Acad. Sci. USA. 87:4966-4970.

4. Tracey, K. J., B: Beutler, S. F. Lowry, J. Merryweather, S. Wolpe, I. W. Milsark, R. J. Hariri, T. J. Fahey III, A. Zentella, J. D. Albert, et al. 1986. Shock and tissue injury induced by recombinant human cachectin. Science (Wash. DC). 234:470-474.

5. Tracey, K. J., Y. Fong, D. G. Hesse, K. R. Manogue, A. T. Lee, G. C. Kuo, S. F. Lowry, and A. Cerami. 1987. Anticachectin/TNF monoclonal antibodies prevent septic shock during lethal bacteremia. Nature (Lond.). 330:662-664.

6. Fischer, E., M. A. Marano, A. Barber, A. A. Hudson, K. Lee, C. Rock, A. S. Hawes, R. C. Thompson, T. V. Hayes, T. D. Anderson, et al. 1991. A comparison between the effects of interleukin-1 $\alpha$ administration and sublethal endotoxemia in primates. Am. J. Physiol. 261:R442-452.

7. Okusawa, S., J. A. Gelfand, T. Ikejima, R. J. Connolly, and C. A. Dinarello. 1988. Interleukin 1 induces a shock-like state in rabbits. J. Clin. Invest. 81:11621172.
8. Waage, A., and T. Espevik. 1988. Interleukin-1 potentiates the lethal effect of tumor necrosis factor alpha/cachetin in mice. J. Exp. Med. 167:1987-1992.

9. Ohlsson, K., P. Bjork, M. Bergenfeldt, R. Hageman, and R. C. Thompson. 1990. An interleukin-1 receptor antagonist reduces mortality in endotoxin shock. Nature (Lond.). 348:550-552.

10. Wakabayashi, G., J. A. Gelfand, J. F. Burke, and C. A. Dinarello. 1991. A specific receptor antagonist for interleukin-1 prevents $E$. coli induced septic shock in rabbits. FASEB (Fed. Am. Soc. Exp. Biol.) J. 5:338-343.

11. Hannum, C. H., C. J. Wilcox, W. P. Arend, F. G. Joslin, D. J. Dripps, P. L. Heimdal, L. G. Armes, A. Sommer, S. P. Eisenberg, and R. C. Thompson 1990. Interleukin-1 receptor antagonist activity of a human interleukin- 1 inhibitor. Nature (Lond.). 343:336-340.

12. Kenney, J. S., M. P. Masada, E. M. Engui, B. M. Delustro, M. A. Mulkins, and A. C. Allison. 1987. Monoclonal antibodies to human recombinant interleukin 1 (IL-1) beta: quantitation of IL-1 beta and inhibition of biological activity. J. Immunol. 138:4236-4240.

13. Michie, H. R., K. R. Manogue, D. R. Spriggs, A. Revhaug, S. O’Dwyer, C. A. Dinarello, A. Cerami, S. Wolff, and D. W. Wilmore. 1988. Detection of circulating tumor necrosis factor after endotoxin administration. N. Engl. J. Med 318:1481-1486.

14. Van Zee, K. J., L. E. DeForge, E. Fischer, M. A. Marano, J. S. Kenney, D. G. Remick, S. F. Lowry, and L. L. Moldawer. 1991. IL-8 in septic shock endotoxemia, and following IL-1 administration. J. Immunol. 146:3478-3482.

15. Fong, Y., K. J. Tracey, L. L. Moldawer, D. G. Hesse, K. B. Manogue, J. S. Kenney, A. T. Lee, G. C. Kuo, A. C. Allison, S. F. Lowry, and A. Cerami. 1989. Antibodies to cachectin/tumor necrosis factor reduce interleukin $1 \beta$ and interleukin 6 appearance during lethal bacteremia. J. Exp. Med. 170:1627-1633.

16. Chizzonite, R., T. Truitt, P. L. Kilian, A. S. Stern, P. Nunes, K. P. Parker, K. L. Kaffka, A. O. Chua, D. K. Lugg, and U. Gubler. 1989. Two high-affinity interleukin 1 receptors represent separate gene products. Proc. Natl. Acad. Sci. USA. 86:8029-8033.

17. Starnes, H. F., Jr., M. K. Pearce, A. Tewari, J. H. Yim, J. C. Zou, and J. S Abrams. 1990. Anti-IL-6 monoclonal antibodies protect against lethal Escherichia coli infection and lethal tumor necrosis factor- $\alpha$ challenge in mice. J. Im munol. 145:4185-4191.

18. McIntosh, J. K., D. M. Jablons, J. J. Mulé, R. P. Nordan, S. Rudikoff, M. T. Lotze, and S. A. Rosenberg. 1989. In vivo induction of IL-6 by administration of exogenous cytokines and detection of de novo serum levels of IL-6 in tumor-bearing mice. J. Immunol. 143:162-167.

19. Preiser, J. C., D. Schmartz, P. Van der Linden, J. Content, P. V. Bussche, W. Buurman, W. Sebald, E. Dupont, M. R. Pinsky, and J. L. Vincent. 1991. Interleukin-6 administration has no acute hemodynamic or hematologic effect in the dog. Cytokine. 3:1-4.

20. Dinarello, C. A., J. G. Cannon, S. M. Wolff, H. A. Bernheim, B. A. Beutler, A. Cerami, I. Figari, M. A. Jr. Palladino, and J. V. O'Connor. 1986. Tumour necrosis factor (cachectin) is an endogenous pyrogen and induces production of interleukin 1. J. Exp. Med. 163:1433-1450.

21. Dinarello, C. A., T. Ikejima, S. J. C. Warner, S. F. Orencole, G. Lonnemann, J. G. Cannon, and P. Libby. 1987. Interleukin 1 induces interleukin 1. I. Induction of circulating interleukin 1 in rabbits in vivo and in human mononuclear cells in vitro. J. Immunol. 139:1902-1910.

22. Fong, Y., M. A. Marano, L. L. Moldawer, H. Wei, S. E. Calvano, J. S. Kenney, A. S. Allison, A. Cerami, G. T. Shires, and S. F. Lowry. 1990. The acute splanchnic and peripheral tissue metabolic response to endotoxin in man. J. Clin. Invest. 85:1896-1904.

23. Cannon, J. G., R. G. Tompkins, J. A. Gelfand, H. R. Michie, G. G. Stanford, J. W. M. Van der Meer, S. Endres, G. Lonnemann, J. Corsetti, B. Chernow, et al. 1990. Circulating interleukin-1 and tumor necrosis factor in septic shock and experimental endotoxin fever. J. Infect. Dis. 161:79-84. 